\title{
CONTRIBUCIÓN DEL TRATADO DE TLATELOLCO AL DESARME NUCLEAR Y A LA NO PROLIFERACIÓN
}

\author{
Héctor GROS ESPIELL*
}

Resumen: Este comentario es acerca del Tratado para la Proscripción de las Armas Nucleares en la América Latina (Tratado de Tlatelolco) — que hoy incluye también a todos los Estados del Caribe-, y que acaba de cumplir 40 años de la apertura a su firma en 1967. El 40 aniversario del Tratado dio lugar a la celebración de un seminario en la ciudad de México, organizado por la Secretaría de Relaciones Exteriores; en este seminario participó el autor, quien brinda un testimonio directo sobre la importancia del Tratado mencionado.

ABSTRACT: This commentary is about the Treaty for the Prohibition of Nuclear Weapons in Latina America (Treaty of Tlatelolco) — which includes also all the Caribbean States-and that has just accomplish 40 years of opening for its signature in 1967. The 40th anniversary of the Treaty gave place to the celebration of a Seminary in Mexico City organized by the Foreign Affairs Secretary. The author, who gives us a direct testimony about the importance of this Treaty, participated in the Seminary.

RÉSUMÉ: Cet commentaire est sur le Traité visant l'interdiction des armes nucléaires en Amérique latine (Traité de Tlatelolco) — que incluent aujourd'hui tous les Etats du Caribéen-et qui viens de cumuler 40 ans de l'aperture de sa signe en 1967. Le 40 anniversaire du Traite a donne lieu à la célébration d'un Séminaire que a été réalise a Mexico et qui a été organise pour la Secrétariat des Relations Extérieurs. L'auteur qui nous donne une évidence directe sur l'importance de cette traite, a participé dans ce séminaire.

* Profesor emérito de la Universidad de la República, Uruguay. 
El Tratado para la Proscripción de las Armas Nucleares en la América Latina (Tratado de Tlatelolco) — que hoy incluye también a todos los Estados del Caribe - acaba de cumplir 40 años de la apertura a su firma en 1967.

$\mathrm{Su}$ importancia como modelo para otras zonas libres de armas nucleares, y su contribución constante a la paz y a las seguridades internacionales, lo situaron y continúan situándolo hoy en el centro del interés político y jurídico.

Su paralelismo con el Tratado de No Proliferación de Armas Nucleares (TNP) — pero sin que nuestro tratado latinoamericano haya afectado el principio de igualdad jurídica de los Estados y no haya sido una expresión de "desigualdad de derechos y obligaciones por el efecto del poder", de discriminación y de desigualdad nuclear, ${ }^{1}$ ni haya estado dirigido a "legalizar una desigualdad", ${ }^{2}$ incluso en lo que se refiere al reconocimiento del derecho al uso pacífico de la energía nuclear (artículo $17 \mathrm{del}$ Tratado de Tlatelolco y artículo IV del TNP)—, ha sido destacado universal y unánimemente, ${ }^{3}$ no sólo inmediatamente después de 1967, sino también en los años posteriores. ${ }^{4}$

Pero además, el Tratado de Tlatelolco posee, por sus características propias, un interés muy especial para la teoría y la práctica del derecho internacional y para su desarrollo progresivo, especialmente en cuanto al derecho de los tratados y a la inclusión del desarme nuclear en el contenido necesario del derecho de gentes. ${ }^{5}$

1 Remiro Brotóns, Antonio, Derecho internacional, Madrid, pp. 95 y 973; Mariño Menéndez, Fernando M., Derecho internacional público, 4a. ed., Madrid, Trotta, 2005.

2 Cot, Jean Pierre y Boniface, Pascal, "Le Controle de l'Armament et le Desarmement”, en Bedjaoui, Mohamed, Droit internacional, bilan et perspectives, París, Pedone-Unesco, 1991, t. 2, p. 870.

3 Por ejemplo, Díez Velasco, Manuel, Las organizaciones internacionales, 14a. ed., Madrid, Tecnos, 2006, p. 787; Dupuy, Pierre-Marie, Droit internacional public, 7a. ed., París, Dalloz, 2004, pp. 647 y 648.

4 Por ejemplo, en el trabajo citado de Cot y Boniface, en el que destacan que el Tratado de Tlatelolco "resulta no de la voluntad de las grandes potencias sino de una iniciativa regional". Cot, Jean Pierre y Boniface, Pascal, op. cit., nota 2, p. 871.

5 He analizado la incidencia del Tratado de Tlatelolco en el derecho internacional, y en especial en el derecho de los tratados, en mi trabajo: El derecho de los tratados y el Tratado de Tlatelolco, México, OPANAL, 1977; y la cuestión del desarme y del desarrollo progresivo del derecho Internacional en mi estudio: "L'Article 26", en Cot, Jean Pie- 
El 40o. aniversario del Tratado de Tlatelolco dio lugar a la celebración de un seminario en la ciudad de México, organizado por la Secretaría de Relaciones Exteriores de los Estados Unidos Mexicanos. Fui invitado a disertar sobre el tema: "Contribución del Tratado de Tlatelolco al desarme nuclear y a la no proliferación".

He pensado que mi intervención podría ser de interés para el Anuario Mexicano de Derecho Internacional, ya que los ocho años en que desempeñé la Secretaría General del Organismo para la Proscripción de las Armas Nucleares de América Latina (OPANAL) (1973-1981) me permitían aportar un testimonio directo sobre de la importancia y significación de esta gran empresa latinoamericana.

Sólo quiero recordar que en lo que escribí años anteriores sobre este tratado y el desarme, ${ }^{6}$ es lo que me permite ahora, mucho tiempo des-

rre et al., La Charte des Nations Unies, Commentaire Article par Article, París, Económica, 1985 (2a. ed.,1991 y 3a. ed., 2005).

6 He aquí mis trabajos: En torno al Tratado de Tlatelolco y la proscripción de las armas nucleares en América Latina, México, OPANAL, 1973; El Tratado de Tlatelolco y el derecho de los tratados, México, OPANAL, 1974; "Francia y el Tratado de Tlatelolco", Revista Internacional y Diplomática, México, abril de 1974; "Una cuestión de interés: la desnuclearización de la América Latina y los territorios latinoamericanos en posesión de potencias extra continentales", Revista Internacional y Diplomática, México, junio de 1974; El Tratado de Tlatelolco, algunas consideraciones sobre aspectos específicos, México, OPANAL, 1976; El Tratado de Tlatelolco: diez años de aplicación (1967-1977), México, OPANAL, 1978; "La Signature du Traité de Tlatelolco par la Chine et la France", Annuaire Français de Droit Internacional XIX, París, 1973; "Le Traité de Tlatelolco, un texte novateur", Le Monde Dipomatique, París, julio de 1973; "Las zonas libres de armas nucleares", Revista de Occidente, Madrid, 3a. época, núm. 6, 1976; "La desnuclearización de la América Latina y la sucesión de Estados en materia de tratados", Revista Internacional y Diplomática, México, marzo de 1976; "Gli Stati Uniti e il Tratato de Tlatelolco", Rivista di Studi Politici Internazionali, Florencia, año XLIV, núm. 4,176, 1977; “Argentina y el Tratado de Tlatelolco", Revista Internacional y Diplomática, México, núm. 317, 1977; Experiencias, problemas y perspectivas del Tratado de Tlateloloco, Buenos Aires, Universidad de El Salvador, 1978; "El Tratado de Tlatelolco", Boletín del Organismo Internacional de Energía Atómica, Viena, vol. 20, núm. 5, 1978 (español, inglés, francés y ruso); "Proscriçao de armas nucleares na América Latina", Revista de Direito Nuclear, Río de Janeiro, núm. 1, t. 2, 1979; Experiencias, problemas, perspectivas del Tratado de Tlatelolco. Política nuclear, Santiago de Chile, Instituto de Estudios Internacionales, 1979; "La France et le Protocolo Aditionnel núm. 1 du Traité de Tlatelolco", Annuaire Français de Droit Internacional, París, 1979; El Tratado de Tlatelolco y el Organismo para la Proscripción de las Armas Nucleares en la América Latina, Washington, Comité Jurídico Interamericano, 1978, Quinto Curso; La seguridad internacional y el Tratado de Tlatelolco, Caracas, 1979; "Los Tratados del Canal de Pa- 
pués, en momentos diferentes y ante realidades cambiantes, pero siempre con base en los mismos principios, volver a expresar mi visión y mi juicio sobre la significación y la proyección regional y universal del Tratado de Tlatelolco y de su aporte a la paz y a las seguridad internacionales.

El 40o. Aniversario del Tratado de Tlatelolco constituye una excelente ocasión, que no puede ser desaprovechada, para reflexionar en los momentos que ahora vivimos, sobre la contribución de este Tratado -resultado de la inteligencia latinoamericana, de los principios que inspiran su política y de su voluntad de luchar realísticamente por la paz y la seguridad, contra las carreras armamentistas, por la justicia y el desarrollo - al desarme nuclear y a la no proliferación.

Esta reflexión ha de ser hecha hoy, necesariamente, en función de la situación internacional actual, pensada sin olvidar la existente en 1967, pero analizada en relación a lo que el mundo es hoy.

Mucho se ha dicho y escrito al respecto en el lapso transcurrido desde que el Tratado para la Proscripción de Armas Nucleares en América Latina se abrió a la firma, en 1967 hasta los días que vivimos. Podría repetirse y compartirse ahora todo lo expresado en esos años sobre la trascendencia jurídica y política del Tratado de Tlatelolco, sobre el positivo aporte conceptual de la idea de creación de zonas libres de armas nuclea-

namá y la zona libre de armas nucleares de la América Latina", en varios autores, Estudios en honor de Adolfo Miaja de la Muela, Madrid, Tecnos, 1979, t. II; "El Tratado de Tlatelolco", Disarmament, Nueva York, United Nations, vol. III, núm. 2, 1980; "Los acuerdos de cooperación del OPANAL", Revista de Estudios Internacionales, Madrid, núm. 4, 1980; La importancia de las zonas libres de armas nucleares, México, American Nuclear Society, 1980; "La no proliferación de armas nucleares en América Latina", Boletín del Organismo Internacional de Energía Atómica, Viena, vol. 2; núm. 3-4, 1980; "Desarme nuclear, perspectivas regionales", Revista de Estudios Internacionales, Madrid, núm. 4, 1981; "Zonas libres de armas nucleares, Renacimiento de Iniciativas para su creación”, Anuario Mexicano de Relaciones Internacionales 1981, México, 1982; "Reservas y declaraciones interpretativas en los protocolos adicionales al Tratado de Tlateloco", Revista Uruguaya de Derecho Internacional, Montevideo, núm. 5, 1982; "Regionalismo y desarme", Anuario de Derecho Internacional 1982, Pamplona, vol. VI, 1983; "Las zonas libres de armas nucleares y la guerra nuclear", Anuario Jurídico X, México, UNAM, 1983; "Desarme regional, zonas libres de armas nucleares y zonas de paz", Revista Española de Derecho Militar, Madrid, núm. 42, 1983; "La guerra nuclear", Anuario Jurídico, México, UNAM, Instituto de Investigaciones Jurídicas, 1983; "La guerra nuclear y las zonas libres de armas nucleares", en varios autores, El peligro de la guerra nuclear, Madrid, Universidad Autónoma, 1984; "La desnuclearización del Pacífico Sur”, La Nación, San José, Costa Rica, 1985. 
res, sobre el mérito excepcional del haber mantenido a América Latina y el Caribe libre de armas nucleares y al margen de la carrera armamentista nuclear, sobre el efecto ejemplarizante que tuvo la iniciativa latinoamericana, sobre el efecto de la contribución política, económica y social, de la proscripción de armas nucleares en una zona habitada del planeta, la latinoamericana, al mundo entero, y sobre la proyección y el sentido del reconocimiento del derecho, debidamente controlado, al uso pacífico de la energía nuclear, como elemento necesario para el desarrollo de los pueblos de los países latinoamericanos y de la humanidad en su conjunto. Todo esto puede y debe recordarse hoy, para compartirlo y aplaudirlo.

Pero este ejercicio repetitivo, aunque interesante y útil, no tendría ahora mayor trascendencia, si se limitara a memorizar lo que ya ha sido reiteradamente dicho.

En cambio puede tener una gran significación actual analizar el Tratado de Tlatelolco y la experiencia de su aplicación, en función de la situación internacional de hoy, en momentos especialmente difíciles, en los que el desarme nuclear y la no proliferación constituyen pautas esenciales para caracterizar el desorden internacional en el que vivimos, la inseguridad en la que se debate la humanidad, y los peligros y amenazas a que la paz se enfrenta.

En efecto, hay que reconocer que hoy el sistema que el Tratado de No Proliferación de Armas Nucleares intentó imponer al mundo, para hacer frente al peligro de la proliferación de armas nucleares, con base en el monopolio de la posesión de dichas armas por unas pocas potencias, está en plena crisis.

Como se dice en un reciente artículo escrito por cuatro prestigiosos políticos y académicos estadounidenses, ${ }^{7}$ es preciso hoy "curar al mundo de la locura nuclear".

Esta "locura" responde a varias y distintas causas. No es posible analizarlas ahora, pero en cambio, es necesario enumerar algunas de las expresiones actuales de tal "locura". Sólo algunas, naturalmente, sin olvidar la carrera nuclear, y la producción y la posesión de estas armas entre las grandes potencias poseedoras.

7 Kissinger, Henry A. et al., "Guérir de la folie nucléaire", Le Monde, Débats, 24 de enero de 2007. 
Pero, asimismo, no puede olvidarse que hay múltiples Estados que poseen armas nucleares además de los previstos en el TNP, y son muchos más los que pueden llegar a tenerlas. Y lo que es más grave, hay Estados poseedores de armas nucleares que no son los previstos en el Tratado de No Proliferación, que tienen una especie de aceptación para que las posean, frente a otros, en cambio, que son estigmatizados o diabolizados por estar o poder llegar a estar en tal situación.

La existencia de países poseedores de armas nucleares, que no son aquellos que pueden tenerlas según el TNP, es particularmente grave para América Latina y el Caribe, porque esos cinco países partes en el TNP son asimismo partes en el Protocolo II del Tratado de Tlatelolco, mientras que los otros países, que no están en tal situación jurídica, pero poseen igualmente armas nucleares, no se han obligado ni a respetar ni a garantizar el estatuto militarmente desnuclearizado de la América Latina y del Caribe.

Asimismo, hecho igualmente grave, pero ligado a lo anteriormente dicho, es que se ha ido difundiendo, cautelosa y parcialmente, la idea, aceptándola sin expresarlo explícitamente, de que poseer armas nucleares es un presupuesto de hecho para que un Estado sea respetado plenamente y esté en condiciones de ser integralmente soberano. De tal modo, se han transformado en lugares peligrosísimos de tensión internacional, sitios en los cuales existirían o se pretende que pudieran existir armas nucleares, no bendecidas, a diferencia de otros lugares, por su aceptación, expresa o tácita, por otra $u$ otras potencias nucleares partes en el TNP.

Por lo demás, la cuestión del uso pacífico de la energía nuclear - cada día más importante ante el dudoso futuro de las fuentes tradicionales de energía - sigue siendo un tema confrontativo. No sólo por su relación con el tema del derecho al medio ambiente, sino por los límites imprecisos entre los procesos científicos, tecnológicos e industriales para el empleo pacífico de la energía nuclear, y aquellos otros relativos al uso bélico o militar.

El tema de la relación entre la posesión de armas nucleares y la tenencia de otras armas de destrucción masiva, especialmente químicas, biológicas y bacteriológicas, pensando en el nexo que une todos estos tipos de armas, y el hecho de que son generalmente las mismas potencias que las que las detienen, constituye asimismo un tema de acuciante y grave actualidad. 
El terrorismo, fenómeno siempre presente en la historia de la humanidad, no tenía en 1967 la significación universal que posee hoy. Sobre todo, esta cuestión del terrorismo no poseía entonces las vinculaciones políticas que hoy tiene ni tenía una estrecha relación, como tiene actualmente, con los conflictos bélicos y con el desarme y el comercio de armas.

Y por último, el tema de la militarización bélica del espacio ultraterrestre, asunto que no podía preverse cuando se elaboró el Tratado de Tlatelolco, aparecido en décadas posteriores, íntimamente vinculado con el uso bélico de la energía nuclear, y que hoy renace, con todos los peligros y amenazas fáusticas que presenta.

Ahora bien, ante estos temas y estas realidades, tan graves y preocupantes para el futuro de la humanidad y para la paz y la seguridad, ¿Cómo deberíamos nosotros hoy considerar la contribución del Tratado de Tlatelolco al Desarme Nuclear y a la No proliferación, tanto respecto de la realidad en la que vivimos como ante el incierto futuro que nos aguarda?

Primero. Creo que es preciso reiterar el pleno convencimiento en la necesidad de la total aceptación y de la ineludible aplicación general de los principios del Tratado de Tlatelolco, expuestos de inmejorable forma en su inspirado Preámbulo.

No nos resistimos a reproducir aquí, algunos párrafos de este Preámbulo tan importante, más hoy que en 1967.

Dice así:

El incalculable poder destructor de las armas nucleares ha hecho imperativo que la proscripción jurídica de la guerra sea estrictamente observada en la practica, si ha de asegurarse la supervivencia de la civilización y de la propia humanidad; Las armas nucleares, cuyos terribles efectos alcanzan indistinta e ineludiblemente tanto a las fuerzas militares como a la población civil, constituyen, por la persistencia de la radiactividad que general, un atentado a la integridad de la especia humana y aún pueden tornar finalmente toda la Tierra inhabitable; La proliferación de las armas nucleares, que parece inevitable a menos que los Estados, en uso de sus derechos soberanos, se autolimiten para impedirla, dificultaría enormemente todo acuerdo de desarme y aumentaría el peligro de que llegue a producirse una conflagración nuclear. 
El establecimiento de zonas militarmente desnuclearizadas está íntimamente vinculado al mantenimiento de la paz y la seguridad en las respectivas regiones.

La desnuclearización militar de vastas zonas geográficas, adoptada por la decisión soberana de los Estados en ellas comprendidos, habrá de ejercer benéfica influencia a favor de otras regiones, donde existan condiciones análogas.

Segundo. Las zonas libres de armas nucleares, que existen actualmente y que cubren algunas partes o regiones del planeta, han constituido y constituyen un aporte esencial a la paz y a la seguridad.

Pero debe pensarse cuanto más trascendente sería esta contribución si hubieran otras zonas libres de armas nucleares, cubriendo otras zonas, en especial en el cercano, en el medio y lejano Oriente.

Es por ello que, aún sabiendo de las dificultades políticas que existen, debería hacerse un gran esfuerzo multilateral, y paralelamente hacer gestiones bilaterales para crear nuevas zonas libres de armas nucleares que cubran esas zonas neurálgicas y críticas, y de especial tensión bélica o prebélica.

Tercero. La no proliferación de armas nucleares ha sido, es y será en el futuro, tanto inmediato como mediato, un objetivo de la comunidad internacional, y por ende, de la humanidad toda. Pero no es un fin en sí mismo, sino un instrumento, un medio para el logro de la paz y la seguridad y para avanzar en el desarrollo económico y social en beneficio de los pueblos y de los individuos. En cuanto instrumento y medio, constituye un aspecto concreto de un objetivo más general y más amplio: el desarme general y completo bajo control internacional. Este deseable objetivo, enormemente difícil de lograr, se enfrenta hoy a una realidad negativa que lo afecta en sus posibilidades, y que se proyecta, también negativamente, en lo que respecta a la situación actual de la no proliferación de armas nucleares a nivel universal.

Es evidente que hoy el mundo asiste, bajo nuevas formas y con diversas excusas, a una, o mejor dicho, a varias carreras armamentistas, que suponen una lamentable desviación de recursos humanos y económicos hacia los armamentos, para usar las palabras del artículo 26 de la Carta de las Naciones Unidas, y que significan todo lo contrario a un verdadero "sistema de regulación de armamentos", preconizado por la Carta en ese artículo. 
Lo que ocurre hoy en materia de desarme es todo lo contrario de lo promovido por el Tratado de No Proliferación de Armas Nucleares, cuyo artículo VI dice: "Cada parte en el Tratado se compromete a celebrar negociaciones de buena fe sobre medidas eficaces relativas a la cesación de la carrera de armamentos nucleares en fecha cercana y al desarme nuclear, y sobre un tratado de desarme general y completo bajo estricto y eficaz control internacional".

Cuarto. Uno de los grandes méritos de las zonas libres de armas nucleares, y por ende un gran beneficio para América Latina y el Caribe, es que la no proliferación que se impone dentro de la correspondiente zona, no tiene ninguna excepción y no supone ningún tipo de discriminación, como consecuencia de lo cual no implica forma alguna de violación o de lesión del principio fundamental de la igualdad jurídica de los Estados.

Quinto. El tema del uso pacífico de la energía nuclear es esencial hoy y será cada día más importante en el futuro de la humanidad y en el mañana de la región latinoamericana y del Caribe.

Por eso es tan importante recordar el artículo 17 del Tratado de Tlatelolco, que dice: "Ninguna de las disposiciones contenidas en el presente Tratado menoscaba los derechos de las partes contratantes para usar, en conformidad con este instrumento, la energía nuclear con fines pacíficos, de modo particular en su desarrollo económico y progreso social".

Este principio, afirmado por el Tratado de Tlatelolco en el artículo antes citado, coincide con lo dispuesto en el artículo IV del TNP, que también es especialmente útil recordar hoy, y que dice:

1. Nada de los dispuesto en este Tratado se interpretará en el sentido de afectar el derecho inalienable de todas las partes en el Tratado de desarrollar la investigación, la producción y la utilización de la energía nuclear con fines pacíficos sin discriminación y de conformidad con los artículos I y II de este Tratado.

2. Todas las partes en el Tratado se comprometen a facilitar el más amplio intercambio posible de equipo, materiales e información científica y tecnológica para los usos pacíficos de la energía nuclear y tienen el derecho de participar en este intercambio. Las partes en el Tratado que estén en situación de hacerlo deberán así mismo cooperar para contribuir, por sí solas o junto con otros Estados u organizaciones internacionales, al mayor desarrollo de las aplicaciones de la energía nuclear con fines pacíficos, especialmente en los territorios de los Estados no poseedores de armas nu- 
cleares partes en el Tratado, teniendo debidamente en cuenta las necesidades de las regiones en desarrollo del mundo.

Es, pues, un derecho "inalienable" que debe ser reconocido y respetado "sin discriminación". Hay que agregar que todos sabemos y lamentamos la forma parcial con que se ha cumplido, o incumplido, con lo dispuesto en este párrafo 2 del artículo IV, antes transcrito, del Tratado de No Proliferación de Armas Nucleares.

El límite entre lo que sirve para el uso pacífico y lo que es el empleo bélico de la energía nuclear no es claro ni preciso. Por eso es tan importante el sistema de controles, como los que nuestro Tratado impone en sus artículos 13, 14, 15 y 16, controles en los que deben jugar un papel esencial el Organismo Internacional de Energía Atómica y el OPANAL o el organismo regional pertinente en el caso de las zonas libres de armas nucleares no latinoamericanas ni caribeñas.

El control del innegable derecho al acceso libre y soberano al uso pacífico de la energía nuclear no puede ser desconocido con peligrosísimas alegaciones políticas, no justificadas multilateralmente, de que podría tratarse cuando se actúa para utilizar pacíficamente la energía nuclear de buscar o realizar formas preliminares o previas para llegar a la preparación del uso nuclear no pacífico.

Estas prácticas obstruccionistas pueden llegar a constituir formas dirigidas para negar en los hechos el derecho al uso pacífico - como derecho de todos y por todos los Estados - en beneficio de sus pueblos, como medio para impulsar el desarrollo económico y social.

Sexto. La creación y existencia de la zona latinoamericana y caribeña libre de armas nucleares, así como las otras que han seguido el ejemplo de Tlatelolco, debe ser apoyado y promovido. Para todos los Estados partes en el TNP, este apoyo y esta promoción resulta del artículo VII de dicho Tratado que dispone: "Ninguna disposición de este Tratado menoscabará el derecho de cualquier grupo de Estados a concertar tratados regionales a fin de asegurar la ausencia total de armas nucleares en sus respectivos territorios".

Séptimo. El análisis del Tratado para la Proscripción de Armas nucleares en América Latina y el Caribe, de su aplicación y sus efectos, no puede ser hecho de manera desvinculada del tema del desarme general y de la carrera armamentista. Ya hemos dicho precedentemente algo al respecto. 
Pero aquí es pertinente tener en cuenta que el Preámbulo de este Tratado destaca "que las zonas militarmente desnuclearizadas no constituyen un fin en sí mismas, sino un medio para alcanzar en una etapa ulterior el desarme general y completo", y afirma que: "El desarme general y completo bajo control internacional eficaz es cuestión vital que reclaman por igual todos los pueblos del mundo".

Hoy, a los 40 años de la apertura a la firma del Tratado de Tlatelolco - que ahora cuenta con 32 Estados partes latinoamericanos y caribeños, y cuyos protocolos I y II han sido firmados y ratificados por todos los Estados extra continentales en condición de hacerlo-, es preciso insistir con orgullo en la importancia y trascendencia de este instrumento. Es necesario seguir bregando por su plena aplicación, por el respeto por las potencias extra continentales que tienen armas nucleares de la zona libre de armas nucleares de América Latina y del Caribe. Se requiere que el Tratado de Tlatelolco se utilice políticamente para que nuestra América exija el respeto de su seguridad, afirme su derecho a no ser objeto de intervenciones o coacciones de especie alguna, y se respete la necesaria acción a favor del desarme general y contra la carrera armamentista.

Pero además, Tlatelolco debe constituir hoy, de manera coordinada con el OIEA, un elemento para asegurar el pleno derecho al uso pacífico de la energía nuclear. Uso que debe ser no discriminatorio ni excluyente, ajeno a las presiones o intereses políticos y económicos externos, que traten de impedir, limitar o condicionar el uso verdaderamente pacífico de la energía nuclear, para imponer interesadamente el subdesarrollo, haciendo no accesible esta energía que puede ser necesaria para el progreso económico y social, y consiguientemente para el bienestar colectivo de los pueblos y los derechos humanos de los seres que los forman.

Para terminar quiero rendir un doble homenaje, que en el fondo constituye uno solo:

A México que tuvo la idea inicial, puso en marcha la iniciativa y luchó por la adopción del Tratado de Tlatelolco y que, luego de lograrlo, combatió sin descanso para lograr su entrada en vigencia y su ratificación por todos los países latinoamericanos y del Caribe, al mismo tiempo que bregó incansablemente para que los protocolos I y II fueran firmados y ratificados por China, Estados Unidos, Francia, Países Bajos, Reino Unido y Unión Soviética (hoy Federación Rusa).

A Alfonso García Robles, de quien tuve el honor de ser amigo, y de trabajar con él; luchador inteligente, hábil y constante para lograr la ma- 
terialización de la idea mexicana y la aplicación del Tratado de Tlatelolco, que fue el primer exponente jurídico, en el tiempo, del contenido y la significación del Tratado - lo que hizo en el curso que dictó en la Academia de Derecho Internacional de La Haya - ; ${ }^{8}$ combatiente permanente por la correcta aplicación del Tratado, quien recibió por todo ello el reconocimiento de su país y de todos los latinoamericanos, y que, al atribuírsele el premio Nobel de la Paz, obtuvo la expresión más alta del agradecimiento de la humanidad por su devoción a la causa del desarme y de la paz.

8 García Robles, Alfonso, "Mesures de désarmement dans des zones particulières: le traité visant l'interdiction des armes nucléaires en Amérique Latine", Recueil des Cours, La Haye, Académie de Droit International, 1971, t. 133, vol. 2. 